\title{
O DISCURSO E A CIDADE: QUATRO ESPERAS
}

\section{MOdesto Carone}

Universidade Estadual de Campinas

\section{Resumo}

Trata-se de uma análise do ensaio "Quatro esperas", incluído no livro O discurso e a cidade de Antonio Candido, em que são analisados textos de Constantino Cavafis; Franz Kafka; Dino Buzzati; e Julien Gracq. Todos apontam para uma percepção ominosa de um mundo-catástrofe.

\author{
Palavras-chave \\ Literatura \\ comparada; \\ Mundo- \\ catástrofe.
}

\section{Abstract}

The aim of the article is the analysis of "Four waitings" ["Quatro esperas"], the second chapter of Antonio Candido's book, The speech and the city [O discurso e a cidade]. The texts chosen by the author are: a poem of Cavafis; a short-story by Kafka; and two novels: the first by Dino Buzzati and the second by Julien Gracq. They point to

Keywords

Comparative
literature;
Catastrophic-
world
the ominous perception of an imminent end of the world.
O discurso e a cidade. São Paulo/Rio de Janeiro, Duas Cidades/Ouro sobre Azul, 2004.

Modesto Carone é professor associado aposentado da Unicamp, escritor e tradutor, autor do romance Resumo de Ana e do livro de contos Por trás dos vidros, ambos pela Companhia das Letras. 
discurso e a cidade é um dos livros mais fortes e impressionantes da galeria de obras-primas de Antonio Candido. Nele as coisas escuras tendem à clareza, segundo a epígrafe emprestada a Eugenio Montale. Basta lembrar que inclui peças definitivas - magistrais pela composição e pelo estilo - como "A dialética da malandragem", sobre Memórias de um sargento de milícias, de Manoel Antonio de Almeida; sobre L'Assommoir, de Émile Zola; "De cortiço a cortiço", sobre o romance de Aluísio Azevedo; "O mundo-provérbio", sobre I Malavoglia, de Giovanni Verga - que deve ter inspirado "La terra trema", de Lucchino Visconti - e outras obras "fora do esquadro" dentro do qual, no entanto, se insere como um engaste de larga envergadura, verdadeiro crepúsculo de ouro, a análise fora-de-série do poema "Louvação da tarde", da fase madura de Mário de Andrade, etc. Sem esquecer, é claro, as "Quatro esperas", objeto central deste trabalho (capítulo II do livro).

Parece fútil discorrer sobre generalidades sem passar em revista (com as lacunas inevitáveis) o "Prefácio" de Antonio Candido (pp. 9-14). O método dessa revista será uma paráfrase crítica, que repercute as "observações críticas" do autor, ou seja: reproduzindo as palavras do intelectual brasileiro a respeito de lances cruciais das suas considerações. Pois quem, melhor que ele, calibra os termos que batem no osso dos ensaios? Nosso objetivo, portanto, é modesto, e a esperança, que ele seja minimamente adequado.

Com essa cautela em vista, não constitui uma ousadia acompanhar a estratégia de fuso da argumentação, que logo de saída anuncia que os ensaios do livro examinam alguns casos de redução estrutural, isto é, o processo por cujo intermédio a realidade do mundo e do ser (a Cidade) se torna, no plano da ficção, componente de uma fatura literária, permitindo que esta seja estudada em si mesma como algo autônomo (o Discurso).

Vale recordar que, na época (anos 70 a 90), andava crispada a divergência entre estruturalismo e análise dialética, que depois foi-se abrandando, até chegar a formulações integradas, como a que Theodor Adorno enuncia, no sentido 
de que o momento social da obra faz parte da sua estética, posição que cruza com as preocupações de Antonio Candido para o bem de todos os que optaram pela literatura exigente.

O que instiga o crítico brasileiro, porém, não é apenas isso, mas a realização prática desse princípio, o que o faz orientar os seus propósitos para uma crítica capaz de mostrar e não só abordar teoricamente (como muitas vezes foi e ainda é o caso), "de que maneira a narrativa se constitui a partir de materiais não-literários a fim de se tornarem aspectos de uma estética regida pelas suas próprias leis e não as da natureza, da sociedade e do ser". Portanto, mimese e contradição, uma vez que as leis a que a obra de arte se submete não são as mesmas que regulam a necessidade na esfera social.

Acontece que, segundo o crítico, "natureza, sociedade e ser parecem presentes em cada página, tanto assim que o leitor tem a impressão de estar em contato com realidades vitais, de estar aprendendo, participando ou negando, como se estivesse envolvido nos problemas que elas suscitam". Quem for contra, que atire a primeira pedra, pois arte e literatura para Candido são formas de conhecimento. Aliás, neste particular, o ensaísta é categórico: "esta discussão é com certeza a mais importante da literatura do ponto de vista do leitor, sendo o resultado mais tangível do trabalho de escrever".

Antonio Candido adverte que os críticos, em geral, "levam em conta a sociedade, a personalidade ou a história" - o que ele também pode realizar com notável perfeição. É por esse motivo que os primeiros "acabam por interessar-se mais pelo ponto de partida (isto é: a vida e o mundo - o grifo é nosso) do que pelo ponto de chegada (o texto ou a elaboração formal dos materiais selecionados)". O interesse do mestre "é diferente", uma vez que "ele se concentra no resultado, não no estímulo ou no condicionamento". Nessa dialética do esclarecimento, ele escreve que "nos ensaios da primeira parte de O discurso e a cidade (sobre Manoel Antonio de Almeida, Émile Zola, Giovanni Verga e Aluísio Azevedo), não há "dados sobre a pessoa e quase nada sobre a sociedade e as circunstâncias históricas, que ficam na filigrana da exposição".

Aqui o leitor precisa preparar-se para uma mudança de maré, já que a bola da vez é a análise ou do comportamento, ou do modo de ser, que se manifestam no interior da escrita, porque foram gestados nela a partir dos elementos oferecidos "pela realidade exterior". A reviravolta já pode acontecer e o sentimento mais expressivo é o de quem passa de um planeta a outro dentro de um mesmo sistema de gravitação. Pois não resta dúvida de que vai-se armando uma inflexão significativa no plano da composição ensaística; em outros termos, nenhum ensaio, refletido a fundo, é inocente, como é o caso da claríssima aventura intelectual empreendida neste livro.

O busílis aparece quando Candido deduz que os textos do capítulo II do livro tendem a ser tão verdadeiros quanto os da primeira parte (o poema "Esperando os bárbaros", de Constantino Cavafis; a narrativa A construção da muralha da China (na verdade, Durante a construção da muralha da China, de acordo com o 
original - de Franz Kafka; O deserto dos tártaros, de Dino Buzzati e O litoral das Sirtes, de Julien Gracq. Por que? Porque, embora descrevam "comportamentos envoltos num certo halo irreal em paragens indefinidas" (os grifos são nossos), eles não reproduzem, mas "transfiguram a realidade".

Seja como for, os dois conjuntos de obras parecem não bater e é daí que emerge uma inesperada interação teórica, no discurso crítico, uma vez que é justamente nesse passo do "Prefácio" que começam a atuar o "fuso" e o vai-e-vem das formulações, como sempre sólidas e sob controle.

Em outras palavras, os "romances naturalistas" (da primeira parte) podem deslizar para as imagens transfiguradoras e o símbolo (como é o caso dos da segunda), ao mesmo tempo que as obras desta última são capazes de transmitir um profundo sentimento da vida - sinal inequívoco de que a questão de fundo e forma é muito mais complexa do que parece. O crítico vai longe e assume, com perícia e precisão, o risco de pôr na mesa um juízo de "aparente incoerência", porque as últimas obras não tiveram nenhum propósito documentário, mas obedeceram à fantasia, penetrando justamente por isso bem no real - "paradoxo inerente à literatura".

Incoerência e paradoxo são palavras pesadas e ricas de sentido, dando a impressão, nesse aspecto, de amortecerem algum choque, pois o que está em jogo aqui é o próprio conceito de realismo. Mesmo descartado "o ponto de vista classificatório dos manuais", ele dá cobertura, no contexto, tanto para os romances do século 19 como para peças literárias do século 20, ou seja, na contracorrente de sua base sócio-histórica, uma vez que aqui está fora de questão qualquer tendência ao formalismo.

Qual a solução encontrada por Antonio Candido? A citação é longa, mas diz tudo o que o leitor precisa entender e incorporar:

[...] a capacidade que os textos possuem de convencer depende mais da sua organização própria que da referência ao mundo exterior, pois este só ganha vida na obra literária se for reordenado pela fatura. Os textos [...] tanto os realistas como os não-realistas suscitam no leitor uma impressão de verdade, porque antes de serem ou não verossímeis, são articulados de maneira coerente".

Com o devido respeito, pode-se indagar o que são textos "não-realistas antes de serem verossímeis". Não serão aqueles que têm uma coerência diversa da coerência dos textos "realistas" marcados pela verossimilhança? Não serão aqueles cuja raiz histórica é distinta - por exemplo, L'Assomoir e Rivage des Sirtes, um ancorado no século 19, o século do "grande realismo" e naturalismo francês, e o outro uma forma literária moderna que, por estar vinculada aos parâmetros socioculturais do século 20, obedece, na fantasia criadora (geralmente exata), a uma outra necessidade artística?

Talvez seja esta a elucidação que faltava para examinar o tema proposto no início deste trabalho, centrado num ensaio excepcional do livro: "Quatro esperas". Não parece ser uma improvisação descabida dar um título ao comentário que se segue. O título poderia ser: "O mundo-catástrofe em quatro tempos". 
Um dos últimos e mais enxutos filmes do cineasta português Manoel de Oliveira - filme falado - narra a odisseia de uma professora de História, que embarca em Lisboa num navio que a deve levar a Bombaim, junto com a filha, ao encontro do marido. Em Marselha, novos passageiros sobem a bordo, formando uma comunidade de intérpretes-mulheres, representadas por artistas famosas (Irene Papas, Catherine Deneuve, Stefania Sandrelli, entre outras). O comandante do navio (John Malkovich) estabelece contato com as passageiras, travando com elas uma conversa civilizada, em línguas europeias que todos entendem. A embarcação ruma para o Oriente Próximo, mas, depois de várias escalas, bem antes de chegar ao destino, que é a Índia, o navio sofre uma pane, ao que parece (ou com certeza) causada por um ato de sabotagem - uma bomba a bordo que não pode ser desativada. Os personagens são obrigados a desembarcar em alto-mar, já no Golfo Pérsico; o comandante permanece no seu posto, pois é o último que pode abandonar a nave; a mãe perde-se da filha e as duas também ficam no barco condenado. O filme termina, sem qualquer comentário, com uma formidável explosão que destroça tudo.

Como interpretar o que aconteceu de maneira tão brutal e inesperada? A resposta mais à mão é que o Ocidente (e as partes do mundo que lhe dizem respeito mais de perto) - o "mundo civilizado" que conhecemos - estão fadados a ir para o espaço sob a ameaça do irracionalismo terrorista. É, por assim dizer, o fim do mundo que, por algum tempo, tantas vezes pressentimos. "Os bárbaros já chegaram" - é o que ocorre dizer para atualizar e trazer à tona o extraordinário poema de Cavafis, que inaugura as "Quatro esperas".

A esta altura é necessário devolver a orientação narrativa do "Prefácio" a Antonio Candido: "A segunda parte (do livro) é na verdade um ensaio único em quatro capítulos, abordando textos que igualmente (como os da primeira) possuem afinidades (...). Eles não têm qualquer toque de consciência social e figuram situações regidas por um sentimento que em nosso tempo se tornou frequente, às vezes obsessivo: a expectativa de perigos iminentes, quase sempre com suspeita de catástrofe".

Cortando caminho, mais ou menos arbitrariamente, não custa lembrar que, para alguns psiquiatras e psicanalistas, a paranoia, doença mental grave, talvez incurável - estudada por Freud, por exemplo, na brilhante análise do "Caso Schreber" - é talvez uma forma de percepção, embora estruturalmente distorcida. Brincando com coisas sérias, seria o caso de dizer que é muito difícil, nos nossos dias, ser normal (o que quer que isso signifique) sem um estoque mínimo de "recursos" paranoides.

Voltemos às considerações do crítico:

"Alimentados por premonições, não observações, esses textos (do cap. I: "Quatro esperas") se desligam da realidade documentária e a dissolvem por meio de uma fantasia livre, criando mundos arbitrários, sem localização histórica nem geográfica precisa, nos quais se infiltram entretanto dramas e angústias de civilizações que conhecemos, no passado e no presente". 
O que importa, neste ponto, é registrar a consideração que embasa o grande ensaio: o poema de Cafavis, o fragmento de Franz Kafka, o romance de Buzzati e a peça lírico-fantasmagórica de Julien Gracq, são na verdade, um "ensaio único em quatro capítulos", aptos a criar "mundos simbólicos", "onde o ser e a política se regem por leis que não negam nem corrigem as do nosso mundo, uma vez que se situam fora dele". Vistas as coisas por outro ponto de vista - que "não nega nem corrige o primeiro" - seria viável afirmar: dentro dele.

Sendo assim, "tanto os textos assentados no documento eventual, quanto os que o transfiguram para criar contextos inexistentes, são capazes de comunicar o sentimento de vida e verdade, porque são literariamente eficazes".

Em 1934, Walter Benjamin escreveu, num ensaio clássico, que em Kafka "as deformações são precisas”. O prosador tcheco, aliás, concebia a literatura como "um espelho que adianta, à maneira de um relógio"; para ele, a criação literária convoca o leitor para uma percepção que existe, mas ainda não aflorou à consciência. Seu objetivo, portanto, não é mostrar (ou duplicar) as nossas formas (transformadas em ideologias), mas tornar visíveis as nossas deformidades.

Essa pretensão é válida para os autores que entram no cenário das "Quatro esperas". O primeiro é Constantino Cavafis, o capítulo intitula-se "Na cidade" e o poema escolhido por Antonio Candido é "À espera dos bárbaros", na valiosa tradução de José Paulo Paes.

O que diz o poema?

Numa cadência clara e limpa - que lembra as "Perguntas de um operário que lê", de Bertolt Brecht - o poeta vai pontuando a narrativa com um refrão funesto: "É que os bárbaros chegam hoje". As interrogações são recorrentes e cessam nas últimas linhas, contrariando as expectativas do leitor e do próprio sujeito lírico: "Sem os bárbaros, o que será de nós?/Ah, eles eram uma solução".

Segundo Antonio Candido, o cenário deve ser "algum lugar do mundo helênico, quem sabe o Oriente Próximo, embebido de cultura grega". O crítico expõe, logo à frente, que em muitos poemas de Cafavis, "é notório o interesse pela situação de beco-sem-saída a que podem chegar os países nos momentos de excessiva maturidade, quando passou o esplendor e os horizontes fecharam" (o grifo é nosso). Em suma: o declínio dos impérios não é de hoje - e tudo indica que o último já esteja à vista. Transpondo de um lugar para outro uma declaração feita no ensaio, "a dúvida do poema é a certeza posterior da história".

Em "À espera dos bárbaros" - diz o ensaísta - "não há referência a um caso histórico concreto". Trata-se, antes, de uma situação genérica, de valor exemplar, "alusiva talvez ao choque destruidor sobre os Estados helênicos do Oriente Próximo, civilizado demais, que não resistiram aos povos mais enérgicos ou primitivos que os atacaram". Citando A. Toynbee, o crítico traz à tona o fato de que os chamados "bárbaros" são definidos como "proletariado externo de culturas menos refinadas que por isso cobiçam a riqueza da civilização. Quando o proletariado externo faz pressão de fora, se houver pressão simultânea exercida de dentro pelo 
proletariado interno (as camadas inferiores oprimidas), configura-se um dos fatores que provocam o fim das civilizações".

Mas neste poema a conjuntura é outra: "a pressão interna é provavelmente exercida pelo cansaço e a descrença, que geram a perda da razão de ser" (grifo nosso). - Tendencialmente, esta seria a motivação profunda dos clowns de Beckett no mundo do circo, que não deixa, metaforicamente, de ser o nosso.

Para Cafavis, de acordo com Candido, o Estado supermaduro "não sabe como resolver seus problemas e obscuramente, com temor misturado de esperança", aspira, em última análise, à pressão externa "que desencadeará o processo como alternativa para o beco-sem-saída". No fecho do poema, "a ironia corrosiva de Cafavis está na decepção paradoxal de que a cidade está salva".

É possível que o amadurecimento para a catástrofe remeta, por caminhos sinuosos, difíceis de mapear, à percepção de Freud no sentido de que o homem tem, na vida, três noivas: a mãe, a esposa e a morte.

Cafavis, porém, não explica nem comenta nada. Na análise do ensaio, ele "apenas constrói a informação pelo método dramático, expresso numa espécie de coral impessoalizado". A expectativa do pavor é descrita friamente, o que eleva a temperatura do poema, servindo de introdução ao "mundo das esperas angustiadas, dos atos sem sentido lógico, da surda aspiração à morte individual e social, que formam alguns dos fios mais trágicos do mundo contemporâneo".

A nosso ver este corte é o mais apto a abrir a porta para as variações sobre o tema nos três textos que se seguem. Chega-se, assim, à segunda espera ("Na muralha") representado pela narrativa A construção da muralha da China, de Franz Kafka.

Mais que um conto, trata-se de um ciclo de histórias na chamada vertente "chinesa" do poeta tcheco. Mas o ensaio de Antonio Candido leva em conta somente as duas sequências conexas que narram, a primeira a construção da muralha; a segunda, a mensagem do imperador.

Alguns especialistas consideram que A construção da muralha da China_forma a peça central do tratamento ficcional sustentado do Oriente como projeção cultural da imaginação europeia. Ela está diretamente relacionada com "Um velho manuscrito", bem como com o tema do colonialismo em "Na colônia penal", "Chacais e árabes" e "O novo advogado". Numerosos paralelos intertextuais sugerem que a narrativa foi influenciada pelas traduções populares da poesia clássica chinesa, publicadas em antologias, além do relato "Na China moderna", que Kafka leu no início da primeira década do século 20.

$\mathrm{Na}$ versão dos estudiosos, esta história foi lida muitas vezes como alegoria dos problemas universais da condição humana. A China, aqui, torna-se um símbolo da própria humanidade: trabalhar nas fronteiras do império chinês, como ocorre aqui, é trabalhar para garantir os limites da existência; Antonio Candido afirma, depois de resumir e examinar em minúcia o relato kafkiano, que ele constrói "alegorias carregadas de sátira sem alegria" e que "a China incaracterística parece fundir-se aos poucos na sociedade geral dos homens". Diz, mais adiante, que 
a peça "talvez se enquadre no vasto espírito de negatividade que avulta desde o Romantismo (...) sendo um elo a mais na cadeia forjada por Kafka para descrever o absurdo e a irracionalidade do nosso tempo" (grifo nosso). Mais uma vez, entra em ação a literatura como "espelho que adianta, à maneira de um relógio", segundo o próprio prosador de Praga.

Além disso, para outros kafkianos, a narrativa está fundada num padrão de preconceitos muito específicos do Ocidente em relação à China desde o Iluminismo. Uma leitura ainda mais radical é capaz de reconstruir a referência do conto à longa história imperial da China, sobretudo à última dinastia (1644-1912) e seu confronto com as potências coloniais do Ocidente. Retrocedendo rapidamente ao "Prefácio" de O discurso e a cidade, é útil lembrar, na pista do ensaísta, que a questão de fundo e forma é mais complexa do que parece. Ou seja: o realismo tout court e as imagens de que ele se serve, podem ser tão verdadeiros quanto o "halo irreal" localizado nas "paragens indefinidas" dos textos considerados nãorealistas.

Retomando a Muralha da China, o narrador conta que ela foi planejada para proteger o povo chinês dos bárbaros do norte; mas ele mesmo reconhece que a maneira de levantar a edificação por partes contradiz esse propósito, uma vez que ficam escancarados longos espaços entre os trechos prontos, tornando precária a função de defesa, que não impede a ação dos supostos nômades predadores. Antonio Candido sintetiza numa frase a situação: "o princípio nega o projeto".

Do ponto de vista estilístico, Kafka expressa esse colapso de história e política mediante contradições insolúveis; a mistificação corre por conta do emprego magistral de sentenças retorcidas, reversões irônicas da argumentação e exageros satíricos.

A alienação entre o governo imperial e os súditos comuns, vinculada a questões históricas mais amplas, como a identidade nacional, é explicada em termos individualistas pela famosa parábola central da narrativa, "Uma mensagem imperial", que Kafka publicou em separado na coletânea Um médico rural ${ }^{1}$. O texto está assentado sobre um duplo paradoxo: embora o imperador tenha enviado uma mensagem a um destinatário definido, ela nunca pode chegar ao seu objetivo, uma vez que o espaço interposto de palácios e pátios sempre repletos de gente é intransponível. Sendo assim, o súdito comum espera ansiosamente pela mensagem, embora o malogro da entrega o impeça de saber que foi ele o destinatário escolhido em primeiro lugar. Não há nenhuma mediação viável entre o imperador - à beira da morte, mas ainda cercado pela aura da infalibilidade divina - e o indivíduo reverente mas politicamente indefeso que vive nas franjas do império. Na perspectiva de Antonio Candido, por outro lado, a própria história é incerta, pois o imperador não manda, não sabe e não pode, como é o caso das sinistras peripécias narradas nos grandes romances do autor, O processo e $O$ castelo.

\footnotetext{
${ }^{1}$ Companhia das Letras. São Paulo, 2. ${ }^{a}$ reimpressão, 2001. Trad. de Modesto Carone.
} 
A terceira espera - "Na fortaleza" - aborda o romance O deserto dos tártaros, de Dino Buzzati. Talvez seja este o ponto central do ensaio de Antonio Candido, visto que a análise dedicada às suas fases e ocorrências é a mais longa, pormenorizada e, em muitos aspectos, a privilegiada entre as "Quatro esperas". As conclusões remetem a todos os demais episódios de "Na fortaleza" (introdução, incorporação à fortaleza, tentativa de desincorporação, o segundo jogo da esperança e da morte), retomados e generalizados num escrutínio tão denso e exato que torna supérflua qualquer paráfrase. O que resta do banquete ao resenhista, além dos ossos, é a tentativa de expor, a quem o lê, as "definições" que coroam a exegese de $O$ deserto dos tártaros.

Assim é que, para o crítico, o livro "pertence à lista dos romances do desencanto" (o grifo é nosso). Eles são capazes de contar como a vida só traz coisas frustradoras, terminando "no balanço negativo dos grandes déficits". Mas - acrescenta ele - ao contrário de certos finais terríveis, como o de Memórias póstumas de Brás Cubas, "o seu desfecho é um caso paradoxal de triunfo na derrota, de plenitude extraída da privação" (grifos nossos). De modo que não se pode considerar o romance de Buzzati uma ficção de desespero; como alguns textos de Hemingway, concebidos sob o signo "grace under pressure", que os redime, também o romance italiano fecha num final iluminado pela esperança, que por mais alucinada que às vezes ela pode ser, existe para compensar a "dor da existência" (Graham Greene). Isto confirma, para o ensaísta, que se trata, também aqui, de "um livro de ambiguidades em vários planos, a começar pelo caráter indefinível do espaço e da época”.

Por esse motivo, o crítico pergunta: onde decorre a ação? A resposta é quase esperada - "num país sem nome, impossível de localizar, como nos contos populares, a despeito dos usos e costumes, bem como do substrato italiano". Mas os nomes do personagem principal e de alguns figurantes (Drogo, Fonzero, Angustina, Stazzi etc.) "contribuem para dissolver a identidade possível do vago universo". Quanto aos tártaros, supõe-se que estão no norte (como na narrativa de Kafka), mas talvez nunca tenham existido, embora constituam uma realidade em um relato no qual a vida é menos um lugar que um estado de espírito. Tudo o que acontece ou não chega a acontecer, é "expresso numa linguagem econômica, severa, recobrindo o pessimismo melancólico do entrecho" - o que mais uma vez aponta para o célebre protocolo kafkiano. A expectativa é a guerra iminente, que nunca vem, a despeito dos rebates falsos. Nesse sentido, a vida na Fortaleza é essencialmente um drama do tempo, marcada pela "ânsia de futuro", capaz de promover movimento e transformação no próprio "centro da paralisia" (J. Joyce, Os dublinenses).

O personagem principal, no fim, já fora da Fortaleza, instalado numa hospedaria do caminho, percebe que a ação militar finalmente foi (ou parece que foi) desencadeada; "amargurado pela ironia incrível da sorte", que o fez passar a vida inteira - inútil - no forte, à espera de um conflito armado, compreende que "a 
morte era a grande aventura inesperada" e não lamenta que ela tenha chegado desse modo, obscura, sem glória guerreira, insignificante e frustradora.

Ponto terminal de uma ação (ou falta de ação) que dura mais de trinta anos, a morte vem destituída do fragor almejado, mas é a única coisa que define o ser de Giovanni Drogo, brilhando no romance como a contradição suprema, pois é através dela que a vida encontra sua afirmação - na "negação absoluta".

O movimento de transcendência se manifesta, para Antonio Candido, numa síntese incisiva: "o sentido da vida de cada um está na capacidade de resistir, de enfrentar o destino (totalmente "absurdo") sem pensar no testemunho dos outros, nem no cenário dos atos, mas no modo de ser"; nesse aspecto "a morte desvenda a natureza do ser e justifica a vida".

A limpidez do estilo faz parte do conteúdo, como foi dito atrás.

$\mathrm{Na}$ quarta parte do ensaio, intitulada "Na Marinha", o livro analisado é O litoral das Sirtes, de Julien Gracq. Segundo Antonio Candido, este romance forma "um curioso par com $O$ deserto dos tártaros, por causa das afinidades, mas sobretudo das diferenças, porque a tônica deste é existencial, enquanto a dele é política, embora de modo peculiar e inesperado".

Estão lançadas as bases do cotejo num ensaio que integra um livro excepcional de literatura comparada, voltado tanto para a literatura brasileira quanto para a europeia, mas sem deixar de lado as convergências e discrepâncias no interior de cada grupo.

O litoral das Sirtes narra, em primeira pessoa, a história de um jovem aristocrata de Orsenna, Aldo, como observador e comissário político junto às magras e antiquadas forças navais em operação - pelo menos em tese - no mar das Sirtes, que separa Orsenna de outro país, o Farguestão.

Aldo é designado para o comando de sua velha fortaleza arruinada, perto da cidade litorânea de Maremma (o termo designa, em italiano, um campo pantanoso perto do mar).

No resumo feito por Antonio Candido, "Orsenna é uma república patrícia visivelmente inspirada em Veneza, governada por uma velha oligarquia, cuja prosperidade foi devida ao comércio, sobretudo com o Oriente, apoiada em forte poderio naval". É patente o parentesco com a Sereníssima República que, íntegra agora, logo mais vai entrar em plena decadência, sem se desligar das tradições do passado.

Conforme a narrativa, Orsenna "está parada e decadente, guardando um tom refinado das civilizações muito maduras em face de um Farguestão vitalizado (como ocorre, por outras vias, no poema de Cafavis) pela força dos seus povos primitivos".

O toque ominoso já foi anunciado: onde as coisas começam mal (mesmo discretamente), não é "absurdo" esperar o pior. O Farguestão, no relato de Gracq, foi dominado por árabes, persas e mongóis, mescla explosiva que o Ocidente, sempre zeloso dos seus poderes e privilégios, associa à barbárie e ao impulso "inato" de destruição. Segundo o ensaísta informa, os farguianos são referidos, pela retó- 
rica oficial de Orsenna, como os "infiéis" - tradicional denominação dada pelos cristãos aos muçulmanos. Eles têm pele escura e no país há nômades sarracenos, o que, no caso, remete à África do norte, de onde as nações ocidentais ricas importaram trabalhadores rudes a preço vil, com a finalidade de competirem entre si pelo mercado mundial. Todas as promessas de cidadania feitas a operários estrangeiros, apesar de inscritos em tratados, não foram nem estão sendo cumpridas, regra de ouro do colonialismo europeu. (Estas últimas afirmações são de responsabilidade minha - M.C.).

O litoral das Sirtes está situado no outro lado do Mediterrâneo, é um golfo da Tunísia e, nos confins de Orsenna há lugares com nomes palestinos, como Engadir e Gaza. Os desertos da região são habitados por grupos nômades - o povo das tendas - e em algumas de suas regiões "manifestam-se tendências messiânicas: uma religiosidade apocalíptica, ritos orientais, visionários e profetas (o grifo é nosso). O leitor não tem necessidade de uma sala dos mapas, nem a ajuda do Monde Diplomatique para se situar na geopolítica desta obra de ficção, publicada em 1951.

Antonio Candido esclarece, aliás, que "o leitor sente em tudo isso um espaço entre Oriente e Ocidente através da mediação veneziana de um Estado que os vincula pela afinidade mercantil". Além do mais, entre Maremma e Farguestão - que lembra hoje Afeganistão, Paquistão e outras nações capazes de "atos de desespero" - existe também uma hostilidade armada, que na filigrana da obra, através de símbolos (como a cor vermelha) degenera em guerra, larvada ou declarada, num estilo etéreo, que parece fluir a contrapelo do que acontece.

Para o crítico, O litoral das Sirtes é "uma narrativa marcada pela dispersão ou imprecisão das referências, mostrando que a interação do romancista francês é diferente da de Buzzati. "Em vez de montar um drama do ser individual", como acontece no livro de Buzzatti, a narrativa de Gracq esboça "uma sociedade, um Estado e uma complicada trama política". Em outras palavras, o crítico afirma que O litoral das Sirtes é um tipo raro de narrativa, onde o indivíduo e a sociedade se desvendam reciprocamente como os dois lados da realidade, segundo uma técnica aparentemente o mais inadequada possível para sugerir mecanismos políticos, pois nela reinam a alusão, a elipse, a metáfora, como se tudo fosse alegoria ou símbolo; como se as pessoas, cenas, lugares, estivessem dissolvidos num halo magnético do tipo que o surrealismo cultiva (os grifos são nossos).

A citação é propositalmente longa para deixar claro como o ensaísta corta no lugar certo: o assunto, o suspense atenuado, a intenção política mais encoberta e tardiamente romântica - tudo conflui numa única frase elucidadora. O que acontece na peça tem o ar da peripécia alusiva de um "folhetim noturno" menos substantivo que o seu par italiano.

Tratando desse confronto, o crítico emprega uma linguagem firme e - por que não? - finamente poética: 
"O litoral das Sirtes é um livro mais difícil e de análise mais delicada que O deserto dos tártaros. Enquanto este é curto e seco (mais moderno?), deixando-se ordenar segundo um esquema plausível, ele é abundante e úmido, fugidio, sem índices evidentes, necessitando releituras atentas para podermos sentir que cada linha é carregada de sentido, e forma o elo de uma cadeia perdida na bruma narrativa, despistadora e insinuante".

Para Antonio Candido a concatenação do texto (marcado por fendas como a própria Muralha da China) é latente, ou seja: "não é formada pela articulação necessária com o momento anterior, mas obedece a algo ominoso, regido por causalidade estranha". Talvez seja justamente esse tipo "desencaixado" de causalidade que aproxima mais O litoral das Sirtes dos textos anteriores que integram as Quatro esperas.

O "estilo burocrático escorregadio" dos acontecimentos ao mesmo tempo obsessivos e rarefeitos de O litoral das Sirtes não impede o reconhecimento de que o protagonista Aldo está quebrando a rotina do "imobilismo da república estagnada" e, na sequência de sinais e indícios suspeitos, pressente, como o leitor, que "alguma coisa se prepara": no povo, os adivinhos profetizam; na aristocracia há um sentimento de catástrofe pendente; na igreja onde floresce o rito oriental, o sacerdote faz uma pregação apocalíptica de Natal. Quem lê a narrativa noturna só dispõe de sugestões vagas, que vão surgindo em ondas sucessivas.

Numa síntese feliz, que capta o texto por dentro e por fora, o crítico declara que "a narrativa insinuante e opulenta, flutuando entre imagens carregadas de implicações, escorre como um líquido escuro e magnético no rumo de catástrofes possíveis, à vista de um horizonte selado pela morte". Neste momento a leitura entra no foco principal de Quatro esperas. Tanto é assim que "do lado das Sirtes estava o que havia de perturbador, e portanto de renovador. A chave do entrecho romanesco já pode ser vislumbrada, pois a missão de Aldo "visava, no fundo, a transformá-lo (o lado das Sirtes) em estopim de uma eventual catástrofe, desejada por ser talvez o meio de sacudir a velha República”. O protagonista , do seu posto, é o instrumento hábil para preparar o provável estado de guerra: o individual e o coletivo se fundem para tornar possível a destruição obscuramente desejada tanto por um como por outro: "O mundo só se justifica às custas da própria segurança", diz um velho estadista no fim do romance. Em outras palavras, "Aldo se incorpora a Orsenna, que existe o tempo todo como força e limite dele próprio".

De modo semelhante ao que acontece no poema de Cafavis, com o qual o crítico começou o seu ensaio, "a longa viagem deságua no risco assumido, que desfechou numa negação suprema, a destruição do Estado, desejada como possibilidade de pelo menos provocar um sinal de vida na sociedade parada".

"Quatro esperas" é um ensaio magnífico e assustadoramente atual. 